\title{
THE USE OF REFLECTIVE PRACTICE TO PROMOTE PHARMACY STUDENTS' METACOGNITION IN A FOUNDATION ANATOMY COURSE
}

\author{
Quenton Wessels, Anneli du Plessis, Adéle du Plessis, Denise Bouman \\ Correspondence to: Dr Quenton Wessels, School of Medicine, Faculty of Health and Medicine \\ University of Namibia, Windhoek, Namibia. Email: qwessels@unam.na
}

\begin{abstract}
Students' ability to characterise their learning approaches has the potential to enhance their overall educational experience and guide educators to tailor their pedagogical approaches. The aim here, through students' reflective practice, is to promote their metacognition. Also, to gain insights to pharmacy students' initial approaches to studying anatomy and their perceived value of anatomy as a subject. The study also aimed to contextually capture students' perceptions on their transition from secondary to tertiary education. This cross-sectional study entailed the use of reflective practice to promote metacognition in first year pharmacy students (Bachelors of Pharmacy students $(n=67)$ ), at the University of Namibia's School of Pharmacy. Results of this study indicate the initial learning approaches of most students to be haphazard. Students used varied, non-departmental resources to guide their learning whilst a few followed structured learning approaches. Results further indicate that students' gradual transition and evolving metacognition appear to start during the initial few months of tertiary education. This transition appears to include feelings of apprehension, uncertainty and distress. Reflective practice creates awareness amongst students of possible gaps in their learning approaches and promote the value of anatomy as an undergraduate subject. Data suggests that the formal incorporation of reflective practice as a metacognitive learning activity promotes students' metacognition by elucidating possible gaps in their learning approaches.
\end{abstract}

Keywords: Learning approaches, anatomy, pharmacy students, reflective practice, metacognition

\section{INTRODUCTION}

The core biomedical subjects, anatomy, physiology and biochemistry, enable students to become proficient in courses such as clinical pharmacy and pharmacology (Reinke et al., 2014). Students typically find these subjects challenging and either adopt an effective study system at tertiary level or fail to do so and ultimately withdraw as a result (Reinke et al., 2014). One primary reason for this is students' inability to self-direct their learning (Naug et al., 2011). Furthermore, the challenges associated with the transition from secondary to tertiary education is sometimes under appreciated. Educators often feel that students are poorly prepared for this change and the need to establish programmes aimed at aiding their transition has been highlighted (Brinkworth et al., 2009). Krause et al. (2005) found that $60 \%$ of first-year university students in Australia feel ill-prepared for life as a university student. The first semester's marks typically serve as a "reality shock" as noted in their study (Krause et al., 2005). Others noted that the first academic year, regardless of the programme, is crucial for students' academic development and it also forms the foundation upon which future academic successes rest (Krause et al., 2005; Reason et al., 2006). Mechanisms need to be in place that allow students to bridge the gap and facilitate the successful integration into the university environment. Yet, strategies are needed that extends beyond the conventional university orientation programs in order to promote students' metacognition (Brinkworth et al.; Hunt et al.; Naug et al., 2011).

Metacognition refers to the learner's mindfulness of the development of their learning. It also refers to the capacity of students to control and manage their own learning (Georghiades, 2004). Students who exhibit metacognitive approaches in their learning, i.e. planned learning activities, scrutinizing their understanding and employing reflective practice, gain a deeper understanding and become autonomous learners (Ross et al., 2006). This autonomy or 
self-regulation is known to be a predictor of academic success (Naug et al., 2011). The application of reflective practice, from a metacognitive perspective, enriches the learning of anatomy, promotes a deeper understanding of anatomical concepts, enhances critical thinking, and promotes learning through the enhancement of confidence (Lachman and Pawlina, 2006). The formal integration of reflective practice further consolidates the gap between theory and practice and inspires student-centred learning. The inclusion of the latter is extremely important for educators wishing to shift from a more didactic approach to fostering selfdirected learning amongst students (Lachman and Pawlina, 2006). Furthermore, the ability to characterise students' learning approaches has the potential to enhance the overall educational experience by guiding educators to tailor their teaching approaches and initiate possible remedial interventions (Romanelli et al., 2009; Atlasi et al., 2017). The aim here, through the formal inclusion of reflective practice, is to provide insights to pharmacy students' initial approaches to studying anatomy, promote their metacognition as well as their perceived value of anatomy as a subject. Furthermore, the study also aimed to contextually capture students' perceptions and reflections of the transition from secondary to tertiary education based on their first-year foundational anatomy programme.

\section{Namibian Context}

The anatomy foundation programme at the University of Namibia (UNAM) consists of three major themes: cells, tissues, and organs and organ systems. This course is concurrently presented to Medicine and Bachelor of Surgery (MBChB) and Bachelor of Pharmacy (BPharm) students during their first semester of their first academic year. It serves to convey fundamental anatomical concepts. The MBChB students typically and without question appreciate the importance of anatomy in their undergraduate degree programme. However, we as educators are often confronted with the BPharm students' interrogations on why they have to study anatomy. In addition, the selection criteria based on academic merit, of these two programmes differ significantly. The $\mathrm{MBChB}$ candidates are required to obtain higher entry scores (a minimum of 35 UNAM points) compared to the BPharm candidates (a minimum of 30 UNAM points). It is for this reason that some BPharm students find the anatomy programme more challenging compared to the MBChB students. We therefore established a reflective element to the first-year anatomy course to aid students to become more aware of their learning. We furthermore wanted to know how their learning approaches evolve when facing the challenges of transition from secondary to

\section{METHODS}

higher education, and how they perceive the importance of anatomy as a subject.

\section{Reflective Practice}

First-year Bachelors of Pharmacy students ( $n=$ 68), at the University of Namibia's School of Pharmacy (SOP), were tasked to complete a reflective assignment as part of their continuous assessment grade for their year one (first semester) foundational anatomy programme. The Department of Anatomy felt that the inclusion of such an assignment would trigger students to reflect upon their learning experience and transition to higher education and thus promote their metacognition. Participant data were collected anomalously and the study was conducted in accordance to the Declaration of Helsinki and its amendments (World Medical Association Declaration of Helsinki, 2013) The breakdown of participants age and gender were as follow: 20 males; 34 females; 14 individuals who did not indicate their gender; and the age range was from 18 to 38 (mean $=20, S D \pm 3.47$, and mode $=19$ ). All students were provided with instructions and online resources to familiarise themselves with Gibb's cycle of reflective practice (Gibbs, 1988). A formal lecture on reflective practice followed their self-directed learning and was aimed at reinforcement and to address any arising concerns and uncertainties. 
First-year Pharmacy students were asked to complete three major tasks, once-off, after their first summative assessment, and consisted of the following:

1. In your own words, reflect on how are you finding year 1 so far? Is Medical School or School of Pharmacy different to what you expected? How and in what way?

2. Reflected on how you prepared for the anatomy assessments? Can you identify some positive features of your learning or new approaches you want to try? Did this reflective exercise help you to identify any areas for improvement? Do you feel confident about your selfdirected learning?

3. Given your experience with attending anatomy lectures and practical sessions, reflect on why you think anatomy is important in your education? In what way do you think your anatomy knowledge will influence your future career?

The reflective tasks were qualitatively analysed through an inductive approach (Burnard et al., 2008). One student did not complete the assignment and a total of 67 reports were randomly assigned to the authors and thematic content analyses were performed in order to identify emerging themes. The process was again repeated to identify further emerging themes and categories (Pope et al., 2000). Processing entailed general familiarisation with the data, the generation of initial codes and validation, the identification of these themes amongst the codes, a review of these themes and the naming of themes, and finally the production of a final report (Burnard et al., 2008). The frequencies of the emerging themes were documented and reported through the use of descriptive statistics.

\section{RESULTS}

Students' reflections on how they were finding their first academic semester were dominated by feelings of distress (Table 1 ). The majority, $(n=44)$ of the respondents stated that they find it challenging to some extent (Table 1). The major contributing factor appears to be the workload with students $(n=25)$ explicitly, stating that they found the quantity of academic work daunting. Some students ( $\mathrm{n}=$ 19) felt that the stresses associated with the onset of their academic career was linked to poor time management whilst surprisingly few ascribed it to social obligations or financial issues. Few students $(n=8)$ did state that they experienced their academic studies exciting or positive (Table 1). Only 14 students unequivocally stated that the reflective exercise aided them in identifying gaps and areas in need of improvement when preparing for assessments. Less than half of the students $(n=32)$ felt that they are confident in their self-directed learning, whilst $(n=10)$ did not. A total of $(n=23)$ did not respond and only ( $n=$ 2) felt unsure.

\section{Table 1: Students' perceptions of the first semester}

\begin{tabular}{|l|c|}
\hline Themes & $\boldsymbol{n}$, frequency(\%) \\
\hline Positive/ecstatic/exciting/amazing/privileged & $8,(12)$ \\
\hline Time/long hours/time management & $19,(28)$ \\
\hline Workload & $25,(37)$ \\
\hline $\begin{array}{l}\text { Negative/stressful/tough/difficult/challenging/hard/over } \\
\text { whelming }\end{array}$ & $44,(66)$ \\
\hline
\end{tabular}

Free text comments (Table 2) provides insight to students' perceptions on the transition from secondary to tertiary education. The perceived differences appear to relate to the educational 
system, mode of academic teaching, volume of academic content, and the relevance of academic work (Table 2). One respondent paraphrased Coombs (1998) and noted that (Coombs and Virshup, 2000): "High school is like a lawn sprinkler. College is like a garden hose. And School of Pharmacy is like a fire hose of information."

The academic resources used by the students varied despite being provided with a formal study/learner guide that outlines the themes, recommended resources and individual learning objectives. There were 12 students who clearly stated that they incorporated the study guide in their preparation for both assessments at the time of the study (Table 3 ). Some students, $(n=9)$ explicitly stated that they did not use the study guide during their preparation. The remaining students $(n=46)$ did not provide feedback on study guide use during their preparatory work (Table 3 ). There were, however, students $(n=14)$ that used alternative approaches such as a nondepartmental study guide and prescribed textbooks or previous test/examination papers (Table 3). Relatively few students $(n=17)$ stated that they used the lecture slides and class notes as a primary resource when preparing for assessments. Several students ( $n$ $=23$ ) found study groups (peer learning) useful during their learning. Students who incorporated online videos/tutorials, specifically YouTubec, totalled 20 (30\%) (Table 3).

Table 2. Students' perceptions of the differences between secondary and tertiary education.

\begin{tabular}{|l|}
\hline Free text comments \\
\hline "Expected dispensing meds" \\
\hline "Undeniable gap between high school and university" \\
\hline "The learning system has changed" \\
\hline "Quite a rollercoaster" \\
\hline "I have grown as a person and as a professional" \\
\hline "The pressure was enormous" \\
\hline "Being used to spoon feeding of high school" \\
\hline "High school mentality is still in me" \\
\hline "The roles of the lecturers is basically to introduce and highlight certain \\
concepts" \\
\hline "But most of all a time filled with discovery, determination and inspiration" \\
\hline "I wish I did a preparatory course before coming to SOP"* \\
\hline "Are pharmacist expected to know the same things as doctors?" \\
\hline "Transition from high school to university has not been easy" \\
\hline "Lecturers teach in a totally different way compared to high school" \\
\hline "In high school teachers are immediately available if you have a problem" \\
\hline
\end{tabular}

* SOP $=$ School of Pharmacy 
Table 3. Learning resources employed by the students.

\begin{tabular}{|l|c|}
\hline Learning approaches & $\begin{array}{c}\boldsymbol{n}, \text { frequency } \\
\text { (\%) }\end{array}$ \\
\hline Flashcards & $1,(1)$ \\
\hline Used study guide & $12,(18)$ \\
\hline Alternative study guide/textbook/previous tests & $14,(21)$ \\
\hline Lecture slides & $17,(25)$ \\
\hline Study groups/peer learning/sharing insights & $23,(34)$ \\
\hline Online videos/tutorials/YouTubeC & $20,(30)$ \\
\hline
\end{tabular}

The second task required students to identify positive features, if any, of their self-directed learning and possible new approaches they employed when preparing for the second assessment opportunity. Many students ( $\mathrm{n}=$ 48) reported that they changed their learning approaches whilst some $(n=22)$ did not do so. Some of the new approaches that were employed or suggested, related to ways to capitalise on didactic lectures (Table 4 ) and included: improved note taking $(\mathrm{n}=2)$; more attention during lectures $(\mathrm{n}=3)$; more attention to detail ( $n=4)$; and ask for clarification ( $n=7)$. Improved resource use included the use of previous question papers $(n=8)$ and additional learning resources $(n=$ 8) (Table 4). Students also noted that their learning approaches changed as follow: studying everyday $(n=8)$; designing a study plan ( $n=9)$, and making use of a study group (peer learning) $(n=23)$ (Table 4$)$.
Students identified various gaps in their learning approaches (Table 5). Of interest is that one student noted that a change in sleeping patterns might be helpful. Students identified a lack of self-management $(n=30)$, including poor time-management as a major hurdle. Inadequacies in their self-directed learning $(n=11)$ including learning too wide and not preparing for the sessions were also documented (Table 5). Students commented that they have "no idea about the content of the modules" and some "find it difficult to balance all my modules". Students $(n=32)$ furthermore identified inadequate use of resources as a gap in their learning approaches and 2 students specifically stated that they studied too wide (Table 5).

\section{Table 4. Positive features in students' self-directed learning.}

\begin{tabular}{|l|c|}
\hline \multicolumn{1}{|c|}{ Areas for improvement } & $\boldsymbol{n}$, frequency (\%) \\
\hline Improved resource use & $16,(24)$ \\
\hline Capitalising on lectures & $16,(24)$ \\
\hline Learning approaches changed & $32,(48)$ \\
\hline
\end{tabular}

Table 5. Perceived gaps and areas of improvement in students' self-directed learning.

\begin{tabular}{|l|c|}
\hline Areas for improvement & $\boldsymbol{n}$, frequency (\%) \\
\hline Inadequate self-directed learning & $11,(16)$ \\
\hline Lack of self-management & $30,(45)$ \\
\hline Inadequate use of resources & $32,(48)$ \\
\hline
\end{tabular}


When asked to provide feedback on their experience of attending anatomy lectures and practical sessions; most students stated that anatomy has a positive influence on their education in several ways. A total of 47 students $(70 \%)$ stated that anatomy serves to provide an understanding how the human body functions (Table 6). In addition, several students stated that anatomy helps them with other related subjects and increases the confidence they have with self-directed learning $(n=5)$ (Table 6). Students believe that anatomy is a fundamental module in for their enrolled programme $(n=19)$ and has a critical role in their studies and prospective careers. The different practical and theoretical dimensions of learning incorporated in the module appealed to many of the students $(n=$ 14) (Table 6).

Finally, students were asked to reflect on how they believe anatomy will influence their future career. Most students $(n=42)$ believe that anatomy will significantly aid them in their future careers as pharmacists by understanding drug interaction with the human body and prospective medical research on a pharmaceutical front. Many students $(n=22)$ believe that anatomy is the foundation of all medical fields (Table 7). Some students ( $\mathrm{n}=$ 5) stated that anatomy teaches them the first ethical considerations medical professionals should have for prospective patients and

critical lab techniques they may need in their

\section{Table 6. Students' perceived value of anatomy in their undergraduate learning}

\section{experience.}

\begin{tabular}{|l|c|}
\hline Emerging themes & n, frequency (\%) \\
\hline Teaches time management/prioritising content. & $5,(7)$ \\
\hline Anatomy is a critical/important/fundamental module. & $19,(28)$ \\
\hline $\begin{array}{l}\text { Aids in learning/reinforces the theory/ } \\
\text { aids with other subjects/understanding relationship between structure and } \\
\text { function. }\end{array}$ & $47,(70)$ \\
\hline
\end{tabular}

Table 7. The value of anatomy in their future career as pharmacists.

\begin{tabular}{|l|c|}
\hline Emerging themes & $\boldsymbol{n}$, frequency (\%) \\
\hline $\begin{array}{l}\text { Only relevant for medical doctors/what is significance for } \\
\text { pharmacists? }\end{array}$ & $3,(4)$ \\
\hline Teach ethical consideration/lab techniques & $5,(7)$ \\
\hline Anatomy is the foundation of all medical fields & $22,(33)$ \\
\hline Supply correct medicine/correct treatment for patients & $42,(63)$ \\
\hline
\end{tabular}




\section{DISCUSSION}

Results from this study indicate that selfmanagement appears to be the primary barrier for many at UNAM's SOP. This leads to workpile up, procrastination and increased stress around and during the time of assessments (Clinciu et al., 2014). The first few months of university overwhelms countless students, and some face personal and/or financial pressures associated with adulthood (Clinciu, 2013; Pasha and Munaf, 2013). Data from this study suggests that some of our first-year students face similar challenges. Students' academic and emotional challenges at UNAM SOP also appear to be linked to a deficit in their secondary schooling. Free text comments suggest that some students carry the burden of an ill-equipped educational system in some schools in Namibia. There appears to be misalignment between secondary schooling and higher education systems, particularly related to mathematics, other basic science subjects, and English (Katjavivi, 2016). Data from this study also suggest that students' transition to become adult learners appear to develop during the initial few weeks of tertiary education. This transition was met with initial feelings of distress for most. An encouraging finding points towards students' transition in their learning approaches. These approaches change over time to include the recommend course material, online platforms and more structured self-directed learning; thus, evolving to become multi-modal. The use of online resources, however, is less than what the authors expected and corresponds to the findings of others (Atlasi et al., 2017). Genderbased differences were not explored and is a possible limitation of this study. This, along with overall academic progress, could be explored by others.

Of importance is one student's comment - "I wish I did a preparatory course before coming to SOP" - reiterates the need to establish a tailor-made induction course. How then, according to Brinkworth and colleagues (2009), "can the expectations of first-year students be better balanced and integrated"? (Brinkworth et al., 2009). Several strategies have come to light during recent years and the work of Krause (2005), for instance, found that a written assignment along with constructive feedback encourages integration of content in text-based courses (Krause et al., 2005). Work on the value of small collaborative groups, by Leveson (1999), demonstrates the value of such an intervention in assisting first-year accounting students with their course material (Leveson. 1999). The value of reflective practice, as exemplified here, serves as a further example of such an intervention. Despite the small number of students acknowledging the value of reflective practice within this study, the authors believe the data presented here indirectly supports the notion. This is achieved by creating awareness of specific gaps and limitations to their learning approaches as well as the importance of anatomy as a subject.

In conclusion the formal incorporation of reflective practice, as demonstrated here, highlights its value in elucidating possible gaps in their own learning approaches and facilitating students' development as adult learners, thus enchanting their metacognition. Reflective practice creates awareness. Such a student-centred educational principle has the potential to provide students with the educational experiences that will indorse the fruition of quality learning outcomes. The findings from this study emphasises the value of student-centred reflective practices as a resource to aid both students and academic staff. Both students and lecturers are able to conceptualise the contextual challenges faced by students, their learning approaches, and subsequently allow realignment of educational practices.

\section{REFERENCES}

1. Atlasi MA, Moravveji A, Nikzad H, Mehrabadi V, Naderian H. 2017. Learning styles and strategies preferences of Iranian medical students in gross anatomy courses and their correlations with gender. Anat Cell Biol 50:255-260. 
2. Brinkworth R, McCann B, Matthews C, Nordström K. 2009. First-year expectations and experiences: student and teacher perspectives. Int J High Educ Educ Plan 58(2):157-73.

3. Burnard P, Gill P, Stewart K, Treasure E, Chadwick B. 2008. Analysing and presenting qualitative data. Br Dent J 204(8):429-32.

4. Coombs RH, Virshup B. 1998. Surviving Medical School. SAGE Publications.

5. Clinciu AI. 2013. Adaptation and Stress for the First-year University Students. Procedia - Soc Behav Sci 78:718-22.

6. Clinciu AI, Cazan A-M. 2014. Academic Adjustment Questionnaire for the University Students. Procedia - Soc Behav Sci 127:655-60.

7. Georghiades P. 2004. From the general to the situated: Three decades of metacognition. Int J Sci Educ 26:365-383.

8. Gibbs, G. 1998. Learning by Doing: A Guide to Teaching and Learning Methods. Oxford Brooks University, Oxford. p 1-134.

9. Hunt L, Kershaw L, Seddon J. 2002. Authentic transitions: The Click Around ECU on-line transition to university program. HERDSA 25:338-353.

10. Katjavivi PH. 2016. Educational transformation in Namibia:Address at the Forum of the Commonwealth Council on Education [Internet]. Available from: http://www.parliament.na/phocadownload/media/2016/speech at commonwealth 16.pdf

11. Krause K, Hartley R, James R, McInnis C. 2005. The first-year experience in Australian universities: Findings from a decade of national studies. Cent Study High Educ Univ Melb. 1115.

12. Lachman N, Pawlina W. 2006. Integrating Professionalism in Early Medical Education: The Theory and Application of Reflective Practice in the Anatomy Curriculum. Clin Anat 19(5):45660.

13. Leveson L. 1999. Small Group Work in Accounting Education: an evaluation of a programme for first-year students. High Educ Res Dev 18(3):361-77.

14. Naug HL, Colson NJ, Donner DG. 2011. Promoting Metacognition in First Year Anatomy LaboratoriesUsing Plasticine Modeling and Drawing Activities: A PilotStudy of the "Blank Page" Technique. Anat Sci Educ 4:231-234.

15. Pasha HS, Munaf S. 2013. Relationship of Self-esteem and Adjustment in Traditional University Students. Procedia - Soc Behav Sci 84:999-1004.

16. Pope C, Ziebland S, Mays N. 2000. Analysing Qualitative Data. BMJ 320:114-6.

17. Reason RD, Terenzini PT, Domingo RJ.2006. First things first: Developing academic competence in the first-year of college. Res High Educ 47(2):149-75.

18. Reinke NB, Llewelyn V, Firth N. 2014. Developing discipline-specific study skills for pharmacy students learning anatomy and physiology. Int J Innov Sci Math Educ 22(1):57-66.

19. Romanelli F, Bird E, Ryan M. 2009. Learning styles: a review of theory, application, and best practices. Am J Pharm 73(1):1-5.

20. Ross ME, Green SB, Salisbury-Glennon JD, Tollefson N. 2006. College students' study strategies as a function of testing: An investigation into metacognitive self-regulation. Innovat High Educ 30:361-375.

21. World Medical Association Declaration of Helsinki. 2013. Ethical principles for medical research involving human subjects. JAMA 310:2191-2194. 